\title{
Case Report \\ Derivative 11;22 (Emanuel) Syndrome: A Case Report and A Review
}

\author{
Madan Gopal Choudhary, ${ }^{1}$ Prashant Babaji, ${ }^{2}$ Nitin Sharma, ${ }^{3}$ Dilip Dhamankar, ${ }^{4}$ \\ Gururaj Naregal, ${ }^{5}$ and Vijay Sunil Reddy ${ }^{6}$ \\ ${ }^{1}$ Department of Pediatrics, SPMC Medical College, Bikaner, Rajasthan 334001, India \\ ${ }^{2}$ Department of Pedodontics, SPPIDMS, Lucknow 226001, India \\ ${ }^{3}$ Department of Pedodontics, Vyas Dental College, Jodhpur, Rajasthan 342001, India \\ ${ }^{4}$ Department of Prasthododntics, NIMS Dental College, Jaipur 302001, India \\ ${ }^{5}$ Department of Periodontics, SJM Dental College, Chitradurga 577501, India \\ ${ }^{6}$ Department of Periodontics, College of Dental Science, Bhavnagar 364001, India
}

Correspondence should be addressed to Prashant Babaji; babajipedo@rediffmail.com

Received 15 January 2013; Accepted 7 February 2013

Academic Editors: C. Aldana-Valenzuela, B. Das, S. M. Dehghani, A. Spalice, S. Tay, and Y.-H. Weng

Copyright (C) 2013 Madan Gopal Choudhary et al. This is an open access article distributed under the Creative Commons Attribution License, which permits unrestricted use, distribution, and reproduction in any medium, provided the original work is properly cited.

Emanuel syndrome (ES) is a rare anomaly characterized by a distinctive phenotype, consisting of characteristic facial dysmorphism, microcephaly, severe mental retardation, developmental delay, renal anomalies, congenital cardiac defects, and genital anomalies in boys. Here, we report a male neonate, with the classical features of Emanuel syndrome.

\section{Introduction}

Emanuel syndrome (ES) is an unbalanced translocation syndrome usually arises through a $3: 1$ meiosis I malsegregation during gametogenesis in a balanced translocation phenotypically normal carrier [1]. Patients with Emanuel syndrome have a distinctive phenotype, which consists of characteristic facial dysmorphism, microcephaly, severe mental retardation, delay in developmental milestone, renal anomalies, congenital cardiac defects, and genital anomalies in boys [2]. While the true mortality rate in Emanuel syndrome is unknown, long-term survival is possible [3]. Emanuel syndrome is also referred to as derivative 22 syndrome, derivative $11 ; 22$ syndrome, partial trisomy 11;22, or supernumerary der $(22) \mathrm{t}(11 ; 22)$ syndrome $[2,4,5]$.

\section{Case Report}

A young mother aged 22 years was reported with a male neonate. The marriage of the infant's parents was consanguineous. The antenatal period of the infant was uneventful except relative less-marked abdominal enlargement and less perception of fetal movements. The infant was delivered at full term by vaginal delivery. On examination, he was small for gestational age as the birth weight was $2.2 \mathrm{~kg}(<$ third percentile), length was $46 \mathrm{~cm}$ ( $<$ third percentile), and head circumference was $32 \mathrm{~cm}$ ( $<$ third percentile). He had a remarkable facial appearance which included prominent forehead with dilated veins, widely separated eyes with downslanting palpebral fissure, broad nasal bridge, prominent philtrum, bilateral large and low-set ears with preauricular pit (Figures 1 and 2). He was also having a small penis $(1.5 \mathrm{~cm})$, but both testes were completely descended. Oral findings observed were high arched palate and micrognathia.

Echocardiography revealed a moderately large, subaortic ventricular septal defect (VSD). The right kidney was missing on abdominal ultrasonography. Hearing assessment revealed a mild hearing loss, but ophthalmological assessment was unremarkable. Karyotyping using G-banding analysis at 550 band levels showed an extra supernumerary marker chromosome (SMC) with supernumerary derivative $(22) t(11 ; 22)$ (Figure 3). To ascertain the origin of this SMC, karyotyping 


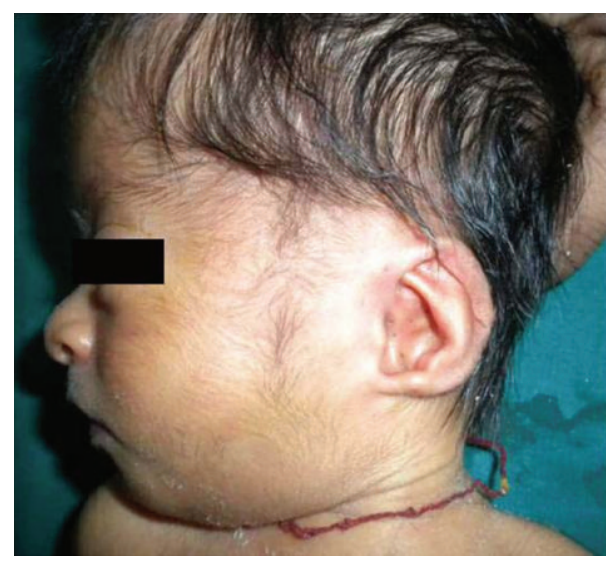

FIGURE 1: The photograph shows the facial features with downslanting palpebral fissure, large and low-set ears with preauricular pit, and micrognathia.

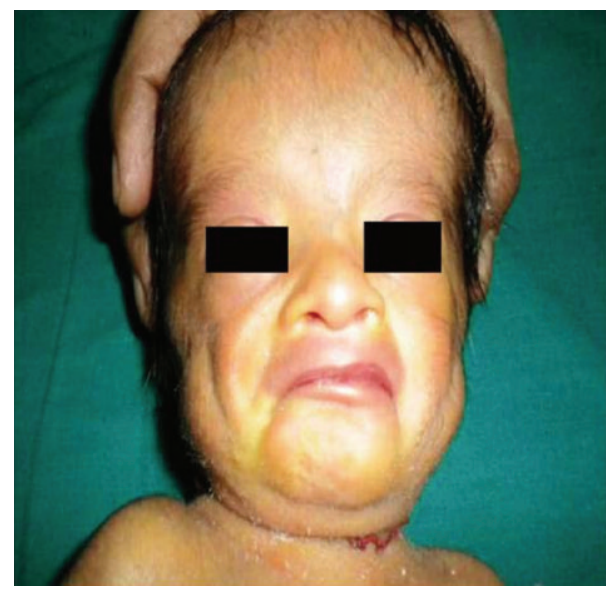

FIGURE 2: The photograph shows the facial features with prominent forehead, widely separated eyes with downslanting palpebral fissure, and micrognathia.

for his parents was performed. The mother was found to be a balanced carrier; 46,XX,t(11;22)(q23.3;q11.2) (Figure 4). During the followup examination for 3 years, he was found to have a significant central hypotonia and developmental delay, and all growth parameters remained well below the third percentile. On followup examinations, he showed developmental delay, and all growth parameters remained well below the third percentile at six months of age.

\section{Discussion}

Emanuel syndrome is an inherited chromosomal abnormality syndrome $[1,14]$. Supernumerary marker chromosomes (SMCs) are frequent findings in cytogenetic studies, with 9\% of SMCs derived from chromosome 22 [15]. This chromosome imbalance consists of either a derivative chromosome 22 [der(22)] as a supernumerary chromosome with the following karyotype: $47, \mathrm{XX},+\operatorname{der}(22) \mathrm{t}(11 ; 22)(\mathrm{q} 23 ; \mathrm{q} 11)$ in females or $47, \mathrm{XY},+\operatorname{der}(22) \mathrm{t}(11 ; 22)(\mathrm{q} 23 ; \mathrm{q} 11)$ in males rarely [3]. It was

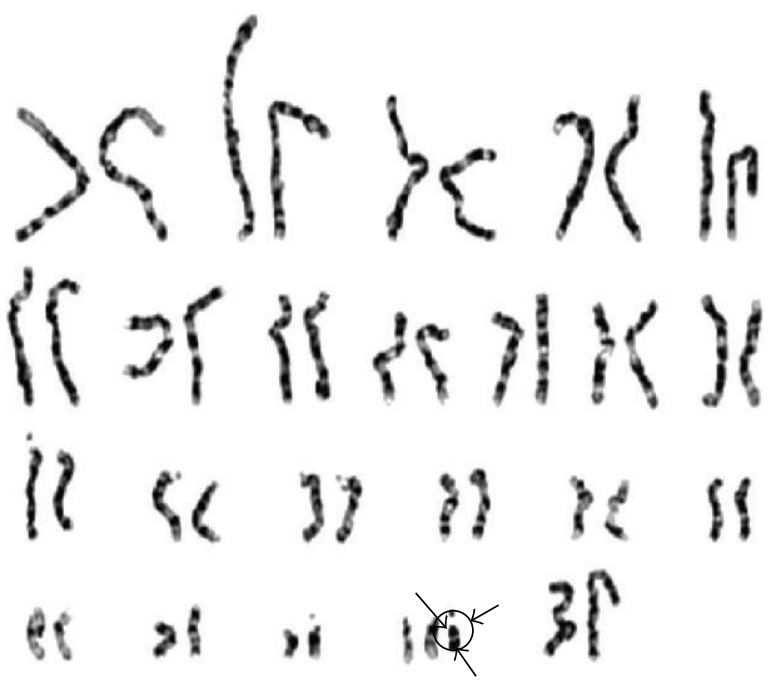

FIGURE 3: The patient's karyotype shows an extra supernumerary chromosome.

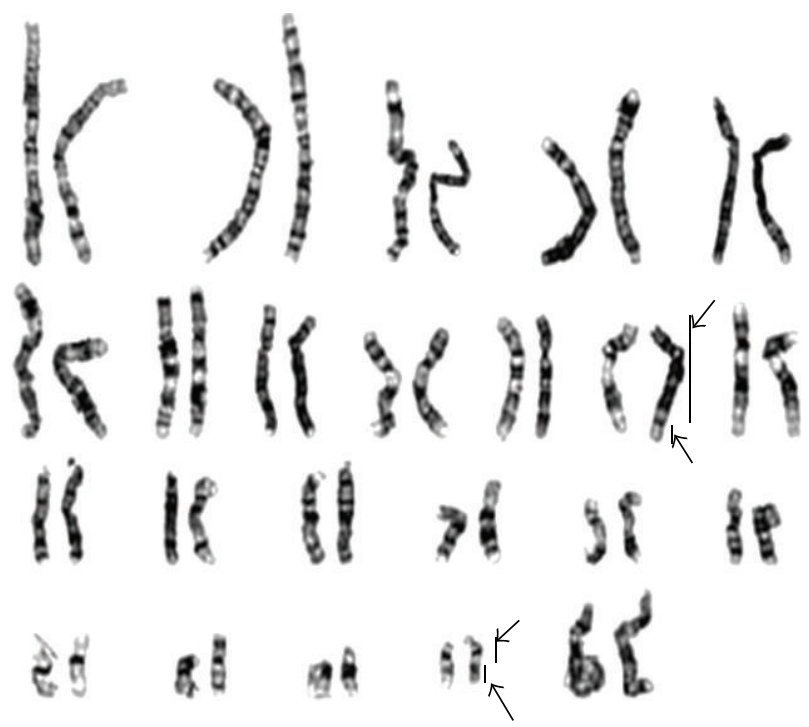

FIGURE 4: His mother's karyotype shows a balanced non-Robertsonian translocation between chromosome 11 and chromosome 22.

named as Emanuel syndrome in 2004 (OMIM no. 609029) $[3,5]$.

The exact incidence is unknown. This is a rare syndrome with reported cases of around 100. Table 1 shows the various reported cases found on Google, PubMed/MEDLINE search [6-13]. Male and female balanced carriers have $0.7 \%$ and $3.7 \%$ risk of having children with supernumerary $\operatorname{der}(22)$, respectively [4]. Patients with ES has a distinctive phenotype, consisting of characteristic facial dysmorphism including prominent forehead, epicanthal folds, downslanting palpebral fissures, broad and flat nasal bridge, long and pronounced philtrum, abnormal auricles ranging from microtia to large ears often associated with a preauricular ear pit and/or skin tags, microcephaly, severe mental retardation, 
TABLE 1: List of reported cases of Emanuel syndrome [6-13].

\begin{tabular}{lccc}
\hline Sl. no. & Reference & Year & No. of cases reported \\
\hline 1 & Zaki et al. & 2012 & 1 \\
2 & Walfisch et al. & 2012 & 5 \\
3 & Kim et al. & 2012 & 1 \\
4 & Carter et al. & 2009 & 63 \\
5 & Toyoshima et al. & 2009 & 1 \\
6 & Emanuel & 2008 & 1 \\
7 & Prieto et al. & 2007 & 1 \\
8 & Crolla et al. & 2005 & 1 \\
9 & Hou & 2003 & 1 \\
10 & Rosias et al. & 2001 & 1 \\
11 & Estop et al. & 1999 & 1 \\
12 & Funke et al. & 1999 & 1 \\
13 & Shaikh et al. & 1999 & 1 \\
14 & Dawson et al. & 1996 & 1 \\
15 & Beedgen et al. & 1986 & 1 \\
16 & Fraccaro et al. & 1980 & 1 \\
17 & Kessel and Pfeifer & 1977 & 1 \\
\hline
\end{tabular}

developmental delay, renal anomalies, congenital cardiac defects, and genital anomalies in boys. Oral findings commonly are micrognathia, cleft, or high-arched palate $[2$, 3]. Evolution of facial dysmorphism with age is not well described, but Medne et al. in 2007 suggested that facial features of ES coarsen over time with micrognathia becoming less pronounced [16]. Almost all the children with ES have global developmental delay and intellectual disability. While most children do not independently ambulate, over $70 \%$ of subjects eventually learned to walk with support. Expressive language is significantly impaired, with rudimentary speech acquisition in only $20 \%$ [3]. Table 2 shows the list of clinical features observed in Emanuel syndrome $[3,4,14,16]$.

The most important differential diagnosis of Emanuel syndrome is the cat eye syndrome (CES). CES usually results from partial tetrasomy 22. Iris coloboma, however, which is a cardinal feature of CES, is not reported in ES. Unlike ES, the majority of individuals with CES have mild or no intellectual impairment [17]. Other differential findings can be Fryns syndrome, Smith-Lemli-Opitz syndrome, or Kabuki syndrome [16]. Clinical testings like chromosomal analysis, FISH testing, whole chromosome paint (WCP), array genomic hybridization (aGH), or MLPA assay can be performed for the diagnosis of this syndrome $[14,18,19]$.

Management involves multidisciplinary team approach involving pedodontist, pediatrician, plastic surgeon, geneticist, gastrologist, speech therapist, urologist, cardiologist, ENT surgeon, and ophthalmologist. Patients with cleft palate have feeding difficulties, which requires feeding plate and surgical closure of cleft palate. The long-term prognosis is directly related to the associated congenital malformations. Highest mortality is in the first few months of life. While the true mortality rate in ES is unknown, long-term survival is
TABLE 2: List of clinical features observed in Emanuel syndrome [3, $4,14,16]$.

\begin{tabular}{|c|c|c|}
\hline Sl. no. & System involved & Clinical features of Emanuel syndrome \\
\hline 1 & $\begin{array}{l}\text { Growth and } \\
\text { development }\end{array}$ & $\begin{array}{l}\text { Pre and postnatal growth retardation, } \\
\text { delayed speech, and language } \\
\text { development (more commonly) }\end{array}$ \\
\hline 2 & Craniofacial & $\begin{array}{l}\text { Microbrachycephaly, prominent } \\
\text { forehead, epicanthal folds, downslanting } \\
\text { palpebral fissures, broad and flat nasal } \\
\text { bridge, long pronounced philtrum, } \\
\text { abnormal auricles, preauricular ear pits } \\
\text { and/or tags } 76 \% \text {, deafness, and otitis } \\
\text { media }\end{array}$ \\
\hline 3 & CNS & $\begin{array}{l}\text { Microcephaly present most commonly, } \\
\text { seizures, failure to thrive, and delayed } \\
\text { pschomotor development }\end{array}$ \\
\hline 4 & Cardiac & $\begin{array}{l}60 \% \text { individuals with congenital heart } \\
\text { defects like atrial septal defect, } \\
\text { ventricular septal defect, Tetralogy of } \\
\text { Fallot, and patent ductus arteriosus }\end{array}$ \\
\hline 5 & Genitointestinal & $\begin{array}{l}\text { Diaphragmatic hernia, anal atresia, } \\
\text { inguinal hernias, biliary atresia, small } \\
\text { penis } 64 \% \text {, and cryptorchidism } 46 \%\end{array}$ \\
\hline 6 & Musculoskeletal & $\begin{array}{l}\text { Centrally based hypotonia most } \\
\text { commonly, congenital hip dislocation, } \\
\text { arachnodactyly, club foot and joint, } \\
\text { syndactyly of the toes, delayed bone age, } \\
\text { and hyperextensibility of joints }\end{array}$ \\
\hline 7 & Oral findings & $\begin{array}{l}\text { Cleft palate } 50 \% \text {, micrognathia } 60 \% \text {, } \\
\text { angular mouth pits, bifid uvula, and } \\
\text { facial asymmetry }\end{array}$ \\
\hline 8 & Immunological & Congenital immunological deficiency \\
\hline 9 & Renal & Renal defects $36 \%$ \\
\hline
\end{tabular}

possible, especially if the patient survives infancy period [3]. The reported case had all the classical features of ES.

Two issues are important in terms of genetic counseling of these families. First, when one parent is a carrier of $t(11 ; 22)$, future pregnancies are at an increased risk for either ES, balanced $t(11 ; 22)$, or another meiotic malsegregation, so prenatal cytogenetic testing should be offered in future pregnancies. Secondly, carrier testing of the unaffected siblings should normally be offered when they have reached adulthood and are able to understand the reproductive implications of being a carrier.

\section{Conclusion}

It is necessary to emphasize the importance of suspecting this syndrome, if a neonate presents with the foresaid facial dysmorphic features and congenital anomalies, so that early diagnosis and timely intervention can be taken in an effort to prolong the survival and improve the lifestyle and more importantly to give appropriate advice regarding genetic counseling to family members. 


\section{References}

[1] T. H. Shaikh, M. L. Budarf, L. Celle, E. H. Zackai, and B. S. Emanuel, "Clustered 11q23 and 22q11 breakpoints and 3:1 meiotic malsegregation in multiple unrelated $t(11 ; 22)$ families," American Journal of Human Genetics, vol. 65, no. 6, pp. 15951607, 1999.

[2] M. Fraccaro, J. Lindsten, C. E. Ford, and L. Iselius, "The 11q;22q translocation: a European collaborative analysis of 43 cases," Human Genetics, vol. 56, no. 1, pp. 21-51, 1980.

[3] M. T. Carter, S. A. S. Pierre, E. H. Zackai, B. S. Emanuel, and K. M. Boycott, "Phenotypic delineation of Emanuel syndrome (supernumerary derivative 22 syndrome): clinical features of 63 individuals," American Journal of Medical Genetics A, vol. 149, no. 8, pp. 1712-1721, 2009.

[4] J. W. Hou, "Supernumerary chromosome marker der (22) t $(11 ; 22)$ resulting from a maternal balanced translocation," Chang Gung Medical Journal, vol. 26, no. 1, pp. 48-52, 2003.

[5] H. J. Kim, Y. M. Kim, H. B. Lee, J. H. Kim, E. J. Seo, and H. W. Yoo, "A case with Emanual syndrome resulting from a maternal translocation," Journal of Medical Genetics, vol. 9, no. 1, pp. 3537, 2012

[6] A. Walfisch, K. E. Mills, B. N. Chodirker, and H. Berger, "Prenatal screening characteristics in Emanuel syndrome: a case series and review of literature," Archives of Gynecology and Obstetrics, vol. 286, no. 2, pp. 299-302, 2012.

[7] M. Toyoshima, C. Yonee, Y. Maegaki et al., "Vertebral fusion in a patient with supernumerary-der (22) t (11;22) syndrome," American Journal of Medical Genetics A, vol. 149, no. 8, pp. 17221726, 2009.

[8] B. S. Emanuel, "Molecular mechanisms and diagnosis of chromosome 22q11. 2 rearrangements," Developmental Disabilities Research Reviews, vol. 14, pp. 11-18, 2008.

[9] J. C. Prieto, N. M. Garcia, F. F. Elder, A. R. Zinn, and L. A. Baker, "Phenotypic expansion of the supernumerary derivative (22) chromosome syndrome: VACTERL and Hirschsprung's disease," Journal of Pediatric Surgery, vol. 42, no. 11, pp. 19281932, 2007.

[10] A. M. Estop, K. M. Cieply, S. Munne, and E. Feingold, "Multicolor fluorescence in situ hybridization analysis of the spermatozoa of a male heterozygous for a reciprocal translocation t(11;22)(q23;q11)," Human Genetics, vol. 104, no. 5, pp. 412-417, 1999.

[11] B. Funke, L. Edelmann, N. McCain et al., "Der(22) syndrome and velo-cardio-facial syndrome/DiGeorge syndrome share a $1.5-\mathrm{Mb}$ region of overlap on chromosome 22q11," American Journal of Human Genetics, vol. 64, no. 3, pp. 747-758, 1999.

[12] A. J. Dawson, A. J. Mears, A. E. Chudley, T. Bech-Hansen, and $\mathrm{H}$. McDermid, "Der $(22) t(11,22)$ resulting from a paternal de novo translocation, adjacent 1 segregation, and maternal heterodisomy of chromosome 22," Journal of Medical Genetics, vol. 33, no. 11, pp. 952-956, 1996.

[13] E. Kessel and R. A. Pfeifer, “47,XY,+der(11;22)(q23;q12) following balanced translocation $\mathrm{t}(11 ; 22)$ (q23; 12$)$ mat. Remarks on the problems of trisomy 22," Human Genetics, vol. 37, no. 1, pp. 111-116, 1977.

[14] M. S. Zaki, A. M. Mohamed, A. K. Kamel, A. M. El-Gerzawy, and M. O. El-Ruby, "Emanuel syndrome due to unusual segregation of paternal origin," Genetic Counseling, vol. 23, no. 2, pp. 319-328, 2012.

[15] J. A. Crolla, S. A. Youings, S. Ennis, and P. A. Jacobs, "Supernumerary marker chromosomes in man: parental origin, mosaicism and maternal age revisited," European Journal of Human Genetics, vol. 13, no. 2, pp. 154-160, 2005.
[16] L. Medne, E. H. Zackai, and B. S. Emanuel, "(Emanuel Syndrome), Gene Reviews- NCBI Bookshelf. Supernumerary der (22)t(11,22) Syndrome," Initial Posting, May 2010, http://www.genetests.org/.

[17] P. P. R. Rosias, J. M. J. Sijstermans, P. M. V. M. Theunissen et al., "Phenotypic variability of the cat eye syndrome. Case report and review of the literature," Genetic Counseling, vol. 12, no. 3, pp. 273-282, 2001.

[18] H. Kurahashi, T. H. Shaikh, E. H. Zackai et al., "Tightly clustered $11 \mathrm{q} 23$ and 22q11 breakpoints permit PCR-based detection of the recurrent constitutional t(11;22)," American Journal of Human Genetics, vol. 67, no. 3, pp. 763-768, 2000.

[19] J. A. S. Vorstman, G. R. Jalali, E. F. Rappaport, A. M. Hacker, C. Scott, and B. S. Emanuel, "MLPA: a rapid, reliable, and sensitive method for detection and analysis of abnormalities of 22q," Human Mutation, vol. 27, no. 8, pp. 814-821, 2006. 


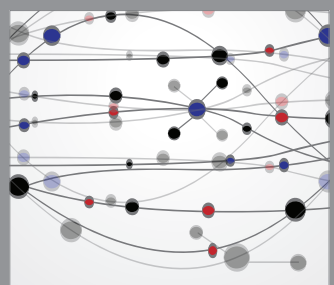

The Scientific World Journal
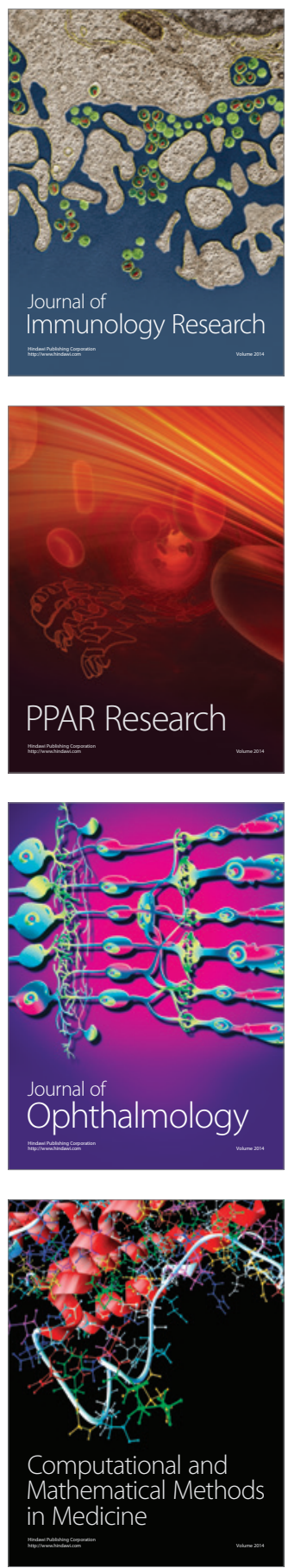

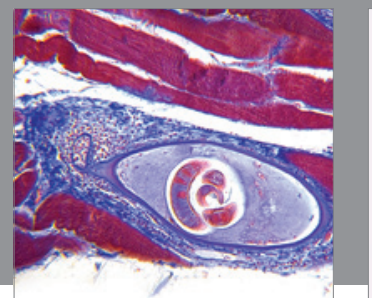

Gastroenterology

Research and Practice
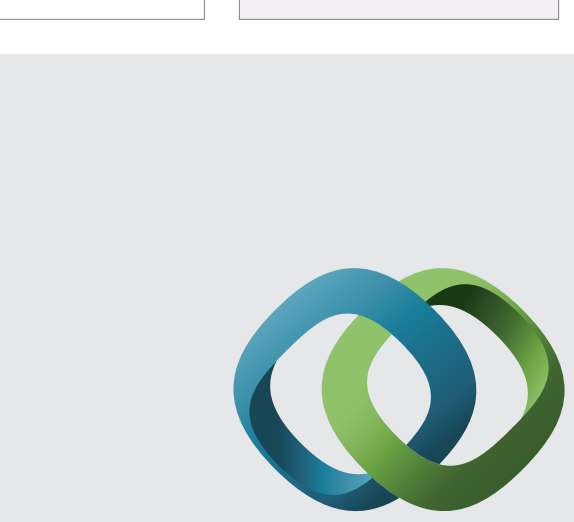

\section{Hindawi}

Submit your manuscripts at

http://www.hindawi.com
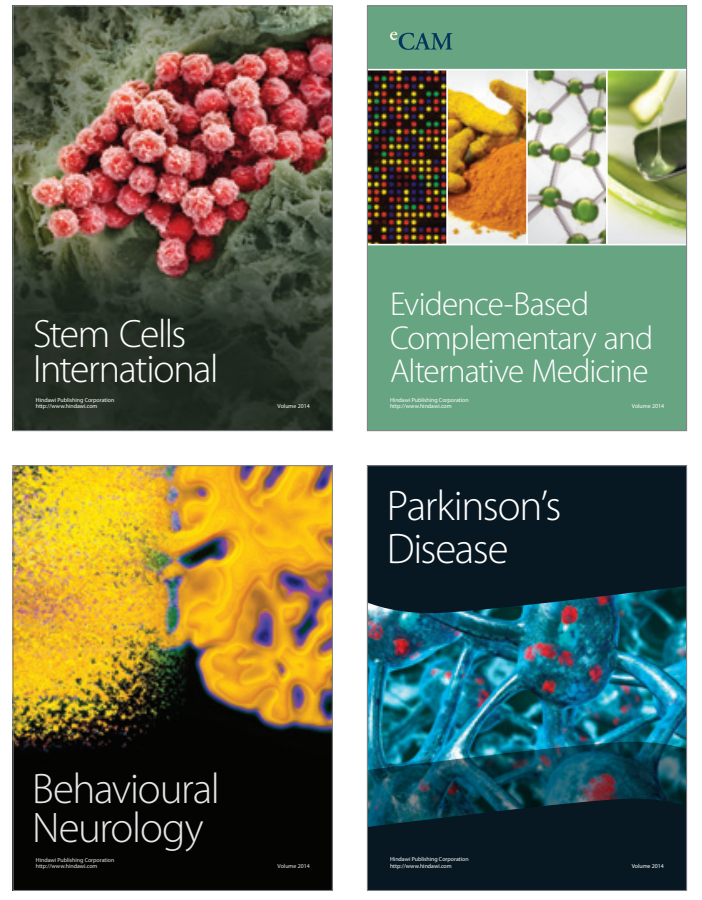
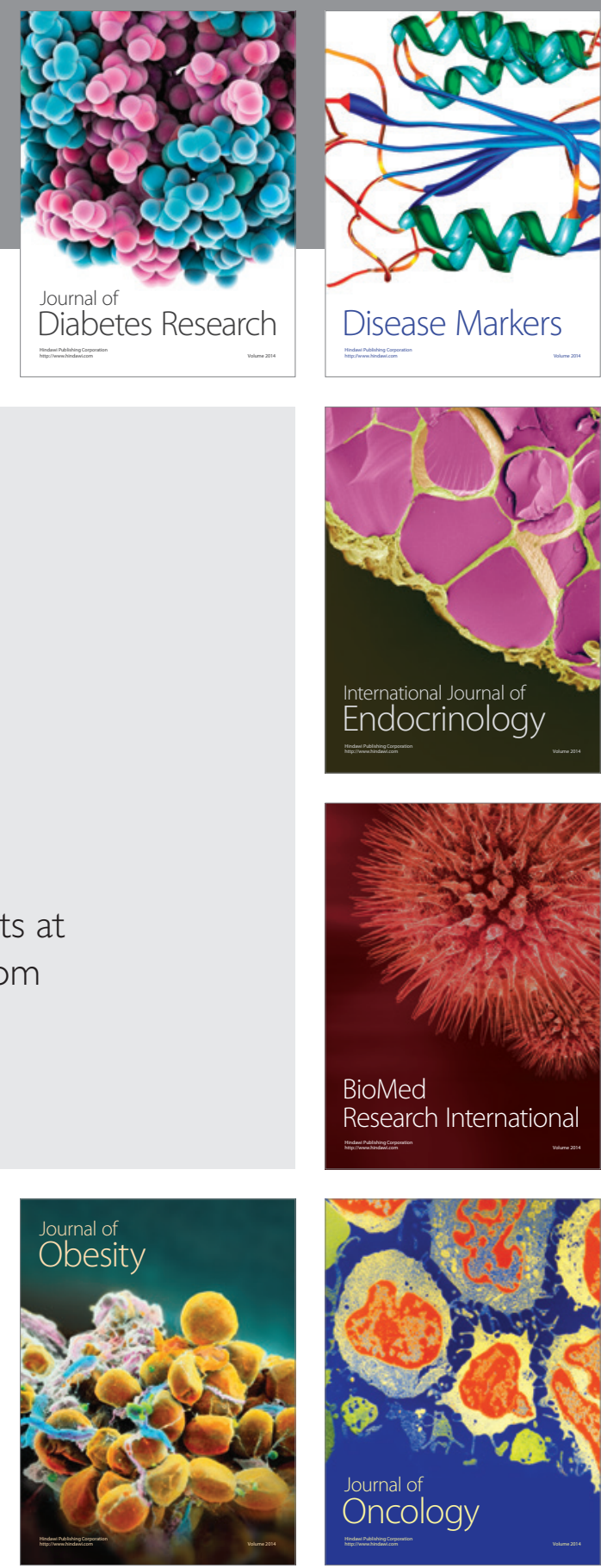

Disease Markers
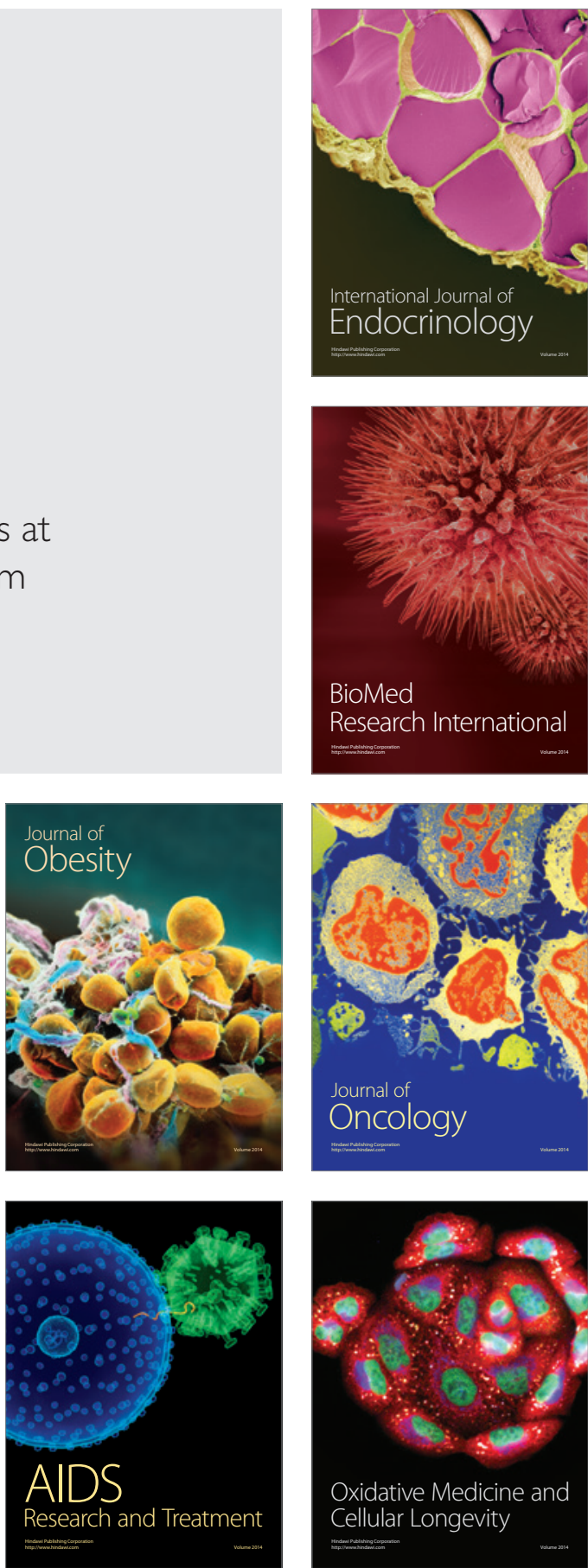